\title{
PERSPECTIVAS BRASILEIRAS NA CONVERGÊNCIA ENTRE O SISBIN E A ZOPACAS
}

\author{
Sérgio Gonçalves de Amorim ${ }^{1}$
}

\section{Introdução}

Esta comunicação objetiva tratar das perspectivas brasileiras na convergência entre o Sistema Brasileiro de Inteligência (SISBIN), que é um arranjo institucional do Estado brasileiro em seu setor de defesa nacional, criado em 1999, e a Zona de Paz e Cooperação do Atlântico Sul (ZOPACAS), que é um mecanismo multilateral de negociação aprovado pela Organização das Nações Unidas (ONU) em 1986, por iniciativa da diplomacia brasileira.

Trata-se, portanto, de analisar a convergências de políticas internas e externas de defesa e segurança de um País em um dado contexto regional.

A ZOPACAS foi criada por iniciativa brasileira junto à ONU, que a aprovou em um contexto em que a Guerra Fria ainda era vigente como paradigma para decisões no âmbito da Política Internacional. À época, internamente o Brasil dava início a um processo de democratização, e a Zona de Paz e Cooperação foi uma das iniciativas de sua nova diplomacia.

Conforme irá se explicitar nesta comunicação, a criação do SISBIN em 1999 é parte desse processo de democratização e de reforma do Estado brasileiro, que no mesmo ano criou o Ministério da Defesa (MD), agregando as três Forças militares em uma única estrutura ministerial. Ainda em 1999, a Casa Militar foi extinta e, em seu lugar, criado o Gabinete de Segurança Institucional da 
Presidência da República (GSIPR), que possui em sua estrutura a Agência Brasileira de Inteligência (ABIN), órgão central do SISBIN.

O Livro Branco de Defesa Nacional (LBDN) (Brasil 2012), documento do MD do Brasil, publicado em 2012, faz menção ao SISBIN e à ZOPACAS, o que justifica a presente pesquisa como uma das formas dos setores acadêmicos, e da sociedade brasileira, conhecer e participar das políticas públicas de segurança internacional e de defesa nacional do País.

Nesse sentido, a seguir, busca-se explicitar as relações entre o SISBIN e a ZOPACAS no pensamento brasileiro de defesa.

\section{A baixa integração e efetividade da ZOPACAS}

No contexto do fim da Guerra Fria, no plano externo, o Brasil propôs com êxito, em 1986, a criação da ZOPACAS, reunindo Países da América do Sul e África, visando evitar a propagação de armamento nuclear e de destruição em massa na região e a intervenção militar de Países de fora da região do Atlântico Sul.

O LBDN (idem, 36) realiza a seguinte apresentação da Zona de Paz e Cooperação:

\footnotetext{
"Criada em 1986 pelas Nações Unidas, a ZOPACAS conta, atualmente, com 24 membros - África do Sul, Angola, Argentina, Benin, Brasil, Cabo Verde, Camarões, Congo, Costa do Marfim, Gabão, Gâmbia, Gana, Guiné, Guiné-Bissau, Guiné Equatorial, Libéria, Namíbia, Nigéria, República Democrática do Congo, São Tomé e Príncipe, Senegal, Serra Leoa, Togo e Uruguai. Em termos diplomáticos, o reforço da ZOPACAS é importante para a defesa do País."
}

Miyamoto (1987), avaliando à época a criação da ZOPACAS, se mostrava cético quanto à sua eficácia e efetividade e apresentava os seguintes motivos:

"[...] a possibilidade de concretização de uma verdadeira zona de paz e de cooperação no Atlântico Sul só se tornará realidade quando alguns pontos forem atendidos: ao nível interno dos Estados, a supremacia do poder civil sobre o poder militar; ao nível mundial, a obediência às convenções internacionais pelas grandes potências, respeitando a soberania dos Países da área; ao nível regional, a resolução do problema das ilhas Malvinas; o sepultamento definitivo dos projetos militares 


\section{Sérgio Gonçalves de Amorim}

expansionistas apoiados nas teorias geopolíticas; na vertente ocidental africana, a resolução do apartheid na África do Sul e a independência da Namíbia com a retirada de tropas sul-africanas desse País. No momento em que estes fatos se tornarem realidades concretas, poder-se-á falar então, sem nenhum receio, em integração regional, em acordos duradouros de qualquer espécie, e em zona de paz nos dois lados do grande lago atlântico."

Em vinte e seis anos da criação da ZOPACAS houve apenas sete reuniões multilaterais, que pouco representaram em medidas efetivas e eficazes para a manutenção da paz e para a cooperação no Atlântico Sul. A primeira reunião ocorreu no Rio de Janeiro, em 1988, em que se investiu em sua operacionalização inicial. A segunda foi em Abuja, na Nigéria, em 1990, em que já se discutiu uma nova funcionalidade da ZOPACAS, sobretudo frente ao fim da Guerra Fria, quando o Atlântico Sul perdeu sua importância relativa, desde que a Zona era como que um contraponto às atividades da Organização do Tratado do Atlântico Norte (OTAN), que por sua vez também perdeu parte de sua razão de existência a partir de tal ocorrência histórica. Atualmente, tal tendência está sendo revista, como se tratará mais adiante.

O terceiro encontro ocorreu em Brasília em 1994, ocasião em que se buscaram novamente novas bases para a justificação da ZOPACAS, sugerindose propostas com ênfase na cooperação econômica, no meio ambiente marítimo e na desnuclearização da região. O quarto encontro ocorreu em 1996, na Cidade do Cabo, na África do Sul, e o quinto encontro, em 1998, em Buenos Aires, na Argentina, em que se aprofundou uma agenda de cooperação que, no entanto, carecia de uma infraestrutura organizacional que pudesse dar sustentação e efetividade à ZOPACAS.

Somente quase uma década depois, o sexto encontro veio a ocorrer em 2007, em Luanda, Angola, contando com a participação de todos os vinte e quatro Países-membros, o que expressava à época uma intenção de que a ZOPACAS viesse a ser revitalizada. Ainda assim, decorreu quase sete anos para que o sétimo encontro ocorresse em Montevidéu, no Uruguai, em janeiro de 2013, ocasião em que se discutiu a instabilidade política na República Democrática do Congo e em Guiné-Bissau, referendando, de certo modo, a quase ineficácia da ZOPACAS em tais situações, desde que como parte da solução para estas questões nacionais sugeriu-se a atuação de outros arranjos multilaterais 
visando à promoção da paz na região, no caso da atuação da União Africana (UA), da Comunidade Econômica dos Estados da África Ocidental (CEDEAO) e da Comunidade dos Países de Língua Portuguesa (CPLP).

Há, portanto, uma multiplicidade de mecanismos multilaterais de negociações internacionais na África, que pode em certa medida tornar inócua a busca de soluções de determinados conflitos regionais por estas vias.

Em síntese, conforme Kornegay (2013, 89), desde sua criação, a agenda da ZOPACAS pode-se resumir aos seguintes pontos:

- $\quad$ Economic cooperation in eradicating poverty by creating partnerships for sustainable development, trade, investment and tourism;

- Crime prevention and combating drug trafficking, illicit trade in small arms and light weapons and transnational organized crime, including piracy;

- Peace, stability and security, including conflict prevention and peacebuilding within the Zone;

- Scientific research, environmental and marine issues;

- Cross-cutting issues and means of implementation;

- And the need for an implementation and follow-up mechanism.

A manutenção do Atlântico Sul em Zona de Paz até o presente momento tem sido antes um atributo do baixo interesse econômico, político e militar na região por parte das potências militares, particularmente daquelas que compõem a OTAN. Entretanto, as recentes descobertas de petróleo e de outros recursos minerais em Países que participam do Atlântico Sul pode mudar este cenário de relativa paz.

\footnotetext{
“Em síntese, há uma África em crescente internacionalização e nada marginal. Ela está no centro de uma concorrência fortíssima de interesses e interessados de todas partes do globo. Se os investimentos externos diretos crescem de forma consistente, oriundos tanto das grandes empresas financeiras e produtivas, é também verdade que esses investimentos estão dirigidos por certa lógica de ocupação territorial e estratégica da África por grandes potências, instituições multilaterais e influentes grupos econômicos globais ancorados em bases estatais." (Saraiva 2008)
}

E, no caso dos Estados africanos, Saraiva (2010) afirma que a África como um todo deve superar quatro desafios históricos, quais sejam: primeiro, as 
"baixas taxas de alternância de poder dentro do continente" que induzem a "regimes dúbios e governos, passando por um processo de institucionalização muito lento"; segundo, a "penetração do narcotráfico internacional" associada aos conflitos armados no continente, transformando a África em um corredor de tráfico de pessoas e drogas; terceiro, as barreiras da exclusão social e pobreza, apesar do significativo crescimento econômico nas últimas décadas; e, quarto, as políticas internas, por vezes sustentadas por "ajudas humanitárias" que mais promovem continuidades que estimulam mudanças, de certo modo, tornando "dependentes" as sociedades africanas de "soluções" exógenas a estes Países, minando a autonomia e efetiva independência desses povos.

A seguir se analisam alguns dos interesses estratégicos da ZOPACAS para o Brasil.

\section{Atuais interesses estratégicos brasileiros na ZOPACAS}

A baixa participação brasileira no âmbito da ZOPACAS pode-se justificar em parte pela perspectiva econômica, pois analisando a política africana do Brasil no pós Guerra Fria, constata-se que "a participação da África na corrente de comércio do Brasil decresce de $7,8 \%$ para $2,81 \%$, no caso das exportações, e de 13,6\% para 3,0\% nas importações" (Ribeiro 2010).

Isso, em parte, justifica ao menos da perspectiva do comércio exterior, uma baixa adesão e efetividade da ZOPACAS logo em sua criação como parte da atuação diplomática brasileira. No governo de Fernando Henrique Cardoso (1995-2002), o Brasil também não se viu interessado em um intercâmbio econômico mais intenso com o continente africano, conforme aponta Ribeiro (idem), desde que "a despeito do fato de vários Países africanos registrarem, entre 1993-2002, uma taxa de crescimento econômico geral de $3,7 \%$, contra menos de 1,0\% em anos anteriores, não se observa mudança substancial na conduta diplomática brasileira para a região".

Os índices de crescimento da economia brasileira na década de 90 foram mais baixos que da década anterior, de acordo com Ribeiro (idem), que acrescenta que em função disso, "o fechamento de postos brasileiros no exterior, e particularmente no continente africano, veio sinalizar, por um lado, as debilidades orçamentárias da União, e, por outro, as prioridades da política 
externa", evidenciando que a ZOPACAS também não foi uma prioridade no período.

No governo Lula, a África voltou a ser objeto da diplomacia brasileira que reabriu embaixadas desativadas, inaugurou representações diplomáticas e proporcionou que Estados africanos abrissem postos diplomáticos no Brasil (ibidem). Assim sendo, para Ribeiro (idem), "tanto a CPLP quanto a ZOPACAS guardam como potencial servirem de lócus de intersecção entre vários processos de integração econômica em curso na região do Atlântico Sul".

Portanto, é prudente levar-se em consideração as palavras do exembaixador brasileiro Luiz A. P. Souto Maior, que ao analisar "A ordem mundial e o Brasil" (2003), aponta que "transformar uma solidariedade pouco mais do que simbólica em participação efetiva num processo concreto de negociação é extremamente árduo", o que pode ser aplicado aos esforços brasileiros, e os demais países do bloco da ZOPACAS em torná-la efetiva.

De uma perspectiva do Brasil, a "agenda brasileira de segurança em relação ao continente africano ainda é pouco expressiva. A política exterior nacional demonstra posicionamento cauteloso com relação ao adensamento de sua diplomacia militar e à participação mais ativa na mediação de conflitos na África", conforme Migon e Santos $(2012,150)$. Os pesquisadores ainda apontam para o fato de que nas relações Brasil- África a "densidade da presença brasileira é aparentemente associada à estabilidade política do País considerado, verificando-se que em áreas mais voláteis a mesma restringe-se à presença militar e, mesmo assim, sob a égide da ONU" (idem, 151). E, complementam sua análise afirmando que,

“A ‘opção pela África’ no âmbito das relações exteriores do Brasil é algo ainda não institucionalizado em sua totalidade. Em outras palavras, verifica-se significativo rol de ações governamentais, o que inclui ações da diplomacia presidencial, sem, contudo ter sido tal realidade efetivamente integrada à Política e à Estratégia nacionais, em especial na área setorial de S\&D [segurança e defesa], formalmente explicitadas." (idem, 151)

Portanto, apesar de sua baixa efetividade a ZOPACAS poderá ser importante para os Países da região como um fórum multilateral para o encaminhamento de questões regionais com o mínimo de interferência de Países 
externos ao Atlântico Sul, sobretudo em um cenário futuro em que os Países desenvolvidos resolvam intervir militarmente visando garantir acesso a mercados, petróleo e recursos minerais, como indica Lima (2011), que aponta para uma discussão no âmbito da OTAN em transformar toda a bacia do Atlântico como área de sua influência. Percebe-se, portanto, que as iniciativas brasileiras neste cenário regional não são isoladas, e que contam com ações de outros grandes atores globais.

Costa (2012) demonstra que há um ponto de inflexão na política externa brasileira que se expande para além da América do Sul em direção ao Atlântico Sul. De todo modo, a projeção do Brasil no Atlântico Sul, particularmente da perspectiva geopolítica, representa um novo cenário estratégico para além de uma integração regional da América do Sul (idem).

"Esse alargamento do seu entorno regional e estratégico corresponde à nova escala de interesses, oportunidades e influência de um País que se consolida como potência econômica mundial e que tem no domínio e na exploração dos recursos do mar uma das mais promissoras fontes de riqueza [...]. Os principais reflexos dessa nova posição são a ampliação da escala e a diversificação do destino final dos produtos, da tecnologia e da cultura brasileira no exterior, além de maior visibilidade e fortalecimento da posição do País na cena internacional, nos organismos da governança mundial e nos temas globais mais relevantes." (idem, 11)

Para Costa (idem) tal ampliação do entorno estratégico brasileiro deuse, sobretudo, em função de seu desenvolvimento científico e tecnológico, permitindo uma ação diplomática até o momento exitosa na constituição da Amazônia Azul, que corresponde às águas do Atlântico Sul que são possessão brasileira.

"Mas, se no campo das pesquisas e da diplomacia o País tem avançado a passos largos, é flagrante sua fragilidade no segundo pilar da sua estratégia de projeção no mundo e no Atlântico Sul em particular, isto é, no campo específico dos assuntos de segurança \& defesa e da capacidade operacional das forças armadas para exercer o poder de dissuasão." (idem, 20) 
Percebe-se, portanto, que o Brasil possui uma política seletiva em relação aos Países africanos, e que sua capacidade de ação em segurança e defesa são limitadas no Atlântico Sul.

A seguir, analisa-se o SISBIN e sua efetividade com vistas a atender parte dessas demandas apresentadas pelas relações estratégicas entre o Brasil e a África na região do Atlântico Sul.

\section{(Des)Articulações das Inteligências no Brasil}

O LBDN nas palavras da presidenta do Brasil é um "marco de transparência nos assuntos de defesa, por meio do qual nossas cidadãs e nossos cidadãos poderão conhecer as ações do Estado nessa área, bem como os desafios do País para aprimorar sua Defesa nas próximas décadas" (Brasil 2012, 7). Ainda em sua mensagem no LBDN, Dilma Rousseff o classifica como "mais um fruto da evolução democrática do Brasil" (idem, 7), e acrescenta que "a Defesa estará cada vez mais presente na agenda nacional [...] Sua leitura indicará, sobretudo, que Defesa e Democracia formam um círculo virtuoso no novo Brasil que estamos construindo" (idem, 7).

Segundo o ministro da defesa do Brasil, Celso Amorim, o LBDN "somase à Estratégia Nacional de Defesa e à Política Nacional de Defesa como documento esclarecedor sobre as atividades de defesa do Brasil" (idem, 8), que devem ser balizadores não apenas das relações entre a sociedade brasileira e suas Forças Armadas, mas de igual modo, do Brasil e os demais Países, dentro e fora da região sul-americana, visando proporcionar transparência política em assuntos militares nacionais e internacionais.

É importante lembrar que o fundamento dos Livros Brancos de Defesa é o exercício da democracia dentro e fora do respectivo País, na medida em que neste documento são explicitados os objetivos em segurança internacional. Com isso, torna-se importante que todos os Países da ZOPACAS apresentem seus respectivos Livros Brancos de Defesa tendo-se em vista os objetivos recíprocos e específicos no âmbito da segurança regional e da defesa nacional de cada País.

O documento citado realiza uma contextualização do ambiente estratégico, e apresenta uma apreciação acerca da realidade do Atlântico Sul na visão do Estado brasileiro, destacando que o "Brasil também dedica, junto a seus vizinhos da África Ocidental, especial atenção à construção de um ambiente 
cooperativo no Atlântico Sul sob a égide da Zona de Paz e Cooperação do Atlântico Sul (ZOPACAS)" (idem, 35) [grifos nossos].

Por outro lado, a LBDN aponta para a "necessidade de fortalecimento dos mecanismos de diálogo entre o MD e o Itamaraty no sentido de aproximação de suas inteligências e no planejamento conjunto" (idem, 49) [grifos nossos].

O MD possui uma complexa estrutura de inteligência que envolve as Forças Armadas e sua participação no Sistema Brasileiro de Inteligência (SISBIN) através do Sistema de Inteligência de Defesa (SINDE), criado através da Portaria Normativa $\mathrm{n}^{\circ}$ 295/MD, de 3 de junho de 2002 (Brasil 2002). Por sua vez, do SISBIN, a Lei n. ${ }^{\circ}$ 9.883/1999 "integra as ações de planejamento e execução das atividades de inteligência do País, com a finalidade de fornecer subsídios ao Presidente da República nos assuntos de interesse nacional".

O LBDN apresenta em nota de rodapé que a Câmara de Relações Exteriores e Defesa Nacional (CREDEN) tem "o encargo de formular políticas públicas e diretrizes de matérias relacionadas com as áreas de relações exteriores e Defesa Nacional do Governo Federal" (idem, 77). O CREDEN é presidido pelo ministro- chefe do GSIPR, ao qual se encontra subordinado a Agência Brasileira de Inteligência (ABIN), órgão central do SISBIN. A ABIN, órgão central da Inteligência brasileira, é subordinado ao GSIPR, ao qual compete, conforme a Medida Provisória n ${ }^{\circ}$ 1.911-10, de 24 de setembro de 1999 (Brasil 1999a),

Art. $6^{\circ}$ Ao Gabinete de Segurança Institucional da Presidência da República compete:

I - assistir direta e imediatamente ao Presidente da República no desempenho de suas atribuições;

II - prevenir a ocorrência e articular o gerenciamento de crises, em caso de grave e iminente ameaça à estabilidade institucional;

III - realizar o assessoramento pessoal em assuntos militares e de segurança;

IV - coordenar as atividades de inteligência federal e de segurança da informação;

V - zelar, assegurado o exercício do poder de polícia, pela segurança pessoal do Chefe de Estado, do Vice-Presidente da República e respectivos familiares, dos titulares dos órgãos essenciais da Presidência da República e de outras autoridades ou personalidades quando determinado pelo Presidente da República, bem como pela segurança dos palácios presidenciais e das residências do Presidente e do VicePresidente da República. 
Amorim (2011), ao analisar a lei que cria o SISBIN/ABIN, aponta que as Atividades de Inteligência (AI) “no País possui[em] prerrogativas para ações sigilosas, o que se por um lado é importante para a salvaguarda de determinados interesses estratégicos para o Brasil, por outro lado, pode abrir precedentes para atuações ilegais do agente público nesse processo", de modo que, nesse campo das ações de qualquer Estado, sempre haverá suspeitas, tanto por parte da sociedade nacional, quanto internacional. Trata-se de um campo contíguo à guerra e à diplomacia, em que posturas totalitárias podem estar presentes e ações na ilegalidade podem ser realizadas no pretexto de segredo de Estado.

Analisando a lei, percebe-se que o GSIPR cuida da segurança institucional do País e da figura do líder da presidência, o que parece ser amplo demais por um lado, e de outro, excessivamente específico para um órgão com status de ministério, o que aponta para certa ambiguidade de atribuições e um possível esvaziamento de suas funções.

Isso porque, talvez, o preciosismo quanto à segurança da figura pessoal do líder da Presidência da República não se conciliem com as atribuições mais amplas relativas aos assuntos de defesa nacional e segurança internacional, tornando ambígua e ampla por demasia as atribuições do GSIPR, podendo esvaziá-lo em sua tentativa em ser um "super-órgão de assessoramento e defesa da Presidência da República", e, por estas ambiguidades, vir a ser ignorado pelo chefe supremo do Executivo, e, por decorrência, pelos outros ministérios, inclusive da defesa e das relações exteriores.

Caso isso ocorra, tanto o GSIPR quanto a ABIN, e, por conseguinte, o SISBIN, careceria de efetividade junto às estruturas de governo e perante o Estado brasileiro.

De todo modo, Amorim (2011) aponta que a MP no 1.911-10/1999 (idem), que trata da "criação do GSI/PR vai explicitando um processo de abertura democrática e de acomodação das estruturas militares no âmbito do exercício do poder executivo, e vai delimitando, no escopo da lei e do Direito, suas prerrogativas de ação legal”.

Cabe lembrar a complexidade das estruturas de governo de um País, que se fragmentam entre diversos grupos de interesse, formatando um campo de governabilidade em que uns grupos podem assumir a prevalência a outros na condução política do Estado e da sociedade. 
Amorim (2012c) discute a difícil integração estatal entre o GSIPR, a ABIN e o SISBIN, "que, por sua vez, é composto por representantes da Casa Civil, do GSI/PR, da ABIN e de outros dez ministérios cuja legislação considera possuir atribuições relativas as $\mathrm{AI}^{\prime \prime}$ (idem), de modo que o problema da integração no âmbito do Estado

"se deve, de certo modo, à complexidade da organização processual do poder político do Estado brasileiro, fracionado em diversos órgãos, cada um deles detentores de uma parcela desse poder, o qual se lastreia parcialmente em conhecimentos privilegiados por certa exclusividade pelo agente público em dada questão. Nem sempre tal agente se encontra disposto a compartilhar esse conhecimento com outros agentes, públicos ou privados, por questões de controle do poder burocrático da máquina do Estado, ou outras, dificultando a integração dos serviços secretos no âmbito do próprio poder estatal (idem)."

Como considera Amorim (idem), o "processo decisório, portanto de comando, é complexo, de modo que nem existem autoritarismos extremos de grupos isolados ou de pessoas, nem decisões sem que reflitam grandes grupos de interesse".

Como decorrência deve-se considerar os diversos níveis de integração das inteligências no SISBIN, fato esse reconhecido em parte no próprio $L B D N$ no tocante às atividades de inteligência do MD e MRE, que precisam se articular melhor via SISBIN, o que neste caso seria extensivos aos demais órgãos integrantes do Sistema. Há que se considerar também os níveis de integração do SISBIN junto ao governo representado pelo chefe do poder Executivo, e às suas atribuições no âmbito das relações exteriores, defesa e inteligência.

"Percebe-se que, apesar dos avanços em cada uma das dimensões institucionais e organizacionais analisadas, há um necessário amadurecimento ainda por se constituir no âmbito das AIs no Brasil, em sua inserção em um Estado Democrático de Direito, visando à segurança e à garantia dos direitos conquistados pela sociedade brasileira." (Amorim 2012c)

No plano interno, o Brasil criou, em 1999, o SISBIN como parte de um processo de democratização da sociedade brasileira, no entanto, Amorim (idem) 
pondera que a sociedade brasileira tem dificuldade em discutir publicamente seus serviços de inteligência, seja por desconhecimentos e/ou por preconceitos:

\footnotetext{
“A ausência de um intenso debate público em torno da institucionalização da AI no Brasil aponta para certo desinteresse da sociedade civil, e mesmo de setores específicos do governo, em relação à temática da segurança institucional, por vezes alimentando estigmas relativos a AI no âmbito do Estado brasileiro contemporâneo."
}

O LBDN aponta, ainda que superficialmente, algumas das diretrizes das políticas públicas brasileiras em defesa, nas relações entre o SINDE/MD, o serviço de inteligência do MRE e o SISBIN/ABIN/GSIPR estabelecidas na legislação brasileira, denotando que o Estado brasileiro busca transparência em suas políticas e ações nestes setores estratégicos. E age, neste sentido, "tendo-se em vista o resguardo das garantias constitucionais que alicerçam a construção da democracia brasileira, desde que há um paradoxo estrutural entre as atividades sigilosas de Estado e a liberdade das pessoas e organizações" (Amorim 2011).

Posto as dificuldades de integração das Inteligências no âmbito do Estado brasileiro, por fim, seguem algumas considerações acerca da efetividade do SISBIN no contexto da segurança regional no contexto do Atlântico Sul.

\section{SISBIN no contexto da segurança regional no Atlântico Sul}

As duas iniciativas da sociedade brasileira em seu processo de democratização, o SISBIN no plano interno, e a ZOPACAS no âmbito externo, não possuem, ainda, uma efetiva convergência em que se considerem a legislação, as políticas e as ações por parte do governo brasileiro.

Da perspectiva brasileira, a convergência entre o SISBIN e a ZOPACAS é complexa: de um lado há uma diversidade de Países que compõem a Zona de Paz e especificidades nas demandas internas e externas de cada uma dessas sociedades; e, de outro, o próprio SISBIN ainda não é um organismo que reflita uma ação integrada do País na área da Inteligência Estratégica, sobretudo, tendo-se em vista o plano das Relações Internacionais.

Há, ainda, para o Brasil, uma demanda pelo aperfeiçoamento nas trocas de informações estratégicas no plano interno via SISBIN, e, mais ainda, no 
plano externo com os Países que compõe a ZOPACAS. Da perspectiva brasileira, o SISBIN e a ZOPACAS, de certo modo, praticamente não se comunicam, deixando de aproveitar sinergias mútuas em defesa e segurança.

No caso do SISBIN, há lacunas que poderiam ser sanadas em ações próativas e preventivas em diversas áreas que envolvem cooperação em torno das AI em cada um dos Países da ZOPACAS. Por outro lado, guardadas as devidas especificidades, a arquitetura legal que fundamenta o SISBIN também poderia servir de inspiração para os demais Países na construção de modelos democráticos para suas respectivas $\mathrm{AI}$, tanto no plano interno, quanto nas relações entre os Países da ZOPACAS. Entretanto, continuariam os desafios processuais da legislação de Inteligência, que são os aspectos vivenciais de cada situação específica, em que ainda não se tem obtido integração e efetividade, como o caso brasileiro demonstra, interna e externamente.

Uma cooperação entre o SISBIN e os demais Países da ZOPACAS permitiria um tratamento mais adequado aos "novos temas de defesa e segurança da região", internamente a cada País e entre eles, o que envolve os recursos minerais (sendo o principal deles o petróleo do Golfo da Guiné e do PréSal brasileiro), as infraestruturas de cada País e as compartilhadas entre eles, o combate ao crime organizado transnacional (narcotráfico, tráfico de armas, o contrabando, tráfico de pessoas), os conflitos envolvendo migração, trabalho e propriedade da terra, os conflitos sócio-ambientais, a própria segurança institucional de cada País, a Ciência, Tecnologia e Inovação a legislação e as políticas nacionais e internacionais para o Mar, entre outros temas relevantes no pós-Guerra Fria.

No entanto, deve-se considerar que no contexto das instituições nacionais e das Relações Internacionais de cada País participante da Zona de Paz, há uma diversidade de interesses em Inteligência de Estado, e seu relacionamento com a sociedade civil também é variado e complexo, e de certo modo, ainda não reflete uma perfeita democracia participativa. Este é um importante condicionante que dificulta ações integradas entre estes diversos serviços secretos na ZOPACAS, apontando para uma fragilidade nesse nível de integração dos sistemas de segurança internacional no Atlântico Sul.

Conciliar as necessidades de defesa e segurança com o avanço democrático, com a garantia aos direitos fundamentais dos cidadãos, no plano 
interno, e com o respeito à soberania dos Estados e à autodeterminação dos povos, no plano externo, têm sido um desafio contemporâneo aos Estados que compõem a bacia do Atlântico Sul, e em todo o mundo.

Internamente a cada um dos Países da ZOPACAS há sempre presente o risco de um tipo de ação de Inteligência servir a projetos de poder, autoritários e violentos, totalmente avessos aos processos democráticos, e quiçá, também aos modos pacíficos de resolução de conflitos regionais, ato que por si próprio afronta os princípios da Zona de Paz e Cooperação.

E, no limite, poderia vir a ser um pretexto para ações militares do grupo dos Países da bacia do Atlântico Sul, quando não de Países de fora da região, na tentativa de dar garantias à estabilidade institucional em um País em que as AI estivessem fora de seus propósitos de ser instrumento da construção democrática da paz.

Lembrando que uma intervenção externa à região também poria por terra os fundamentos da ZOPACAS. Portanto, se em apenas um País as AI não guardassem o respeito às instituições democráticas e à soberania dos demais povos, tal fato suscitaria constantes desconfianças não apenas na respectiva nação, mas, no caso da ZOPACAS, em todos os demais parceiros da bacia do Atlântico Sul, trazendo instabilidades para a paz na região.

Amorim (2012a) considera que as atividades de espionagem/contraespionagem perpassam as sociedades humanas na perspectiva histórica e antropológica, e sempre suscitam desconfianças, promovem traições e o medo, e contribuem para posturas etnocêntricas e xenófobas, que formam como que um fundo cultural, um ethos e um pathos, que merecem uma atenção nem sempre devida no âmbito das relações de poder.

\footnotetext{
"Desse modo, apesar de todos os exageros que possam ser considerados no exercício desses tipos de atividades, as sociedades que as puseram em movimento estavam buscando o que acreditavam ser o melhor para elas próprias, por mais contraditórias e ambíguas que possam ter sido as formas de tais intentos. De fato, a violência possui suas ambiguidades e contradições, desde que serve para os mais diversos propósitos, entre um leque de possibilidades que vão da aniquilação de um grupo humano à sua própria estruturação."
} 
Forças humanas, integradoras e destruidoras ao mesmo tempo, que ganham dimensões institucionais, nacionais, continentais e mundiais, e que se fazem presentes na paz e na guerra, e compõem parte da vitalidade das relações humanas e da política em diversas escalas.

Amorim (2012b) analisando algumas das perspectivas brasileiras de cooperação democrática em segurança regional do SISBIN no contexto da UNASUL pondera que

“As Atividades de Inteligência (AI) consideradas de um ponto de vista bastante amplo e genérico apontam para um ethos e um pathos intimamente relacionados à natureza do exercício do poder e do governo em uma sociedade [...] Este ponto de vista é uma forma de se compreender as AI em cada País, exercida em conformidade com os objetivos estratégicos traçados por seus respectivos governos e sociedades, o que certamente revelará posições antagônicas entre Estados, mas também interesses comuns, e, por vezes, construtos para a paz e segurança em uma dada região."

Afastar-se das desconfianças mútuas e aproximar-se da cooperação SISBIN/ZOPACAS envolve uma quebra de paradigmas em relação aos fundamentos das próprias AIs, que em um contexto clássico das Relações Internacionais seriam um tema interno a cada País, ainda que possa haver repercussões no exterior, das ações em Inteligência de cada Estado. Este é também o caso das Forças Armadas e dos respectivos ministérios das Relações Exteriores de cada País, que são organismos internos cujas ações também podem repercutir no plano da Segurança Internacional. A construção de outra mentalidade no campo das AI, em geral e no contexto da ZOPACAS em particular, teria um papel fundamental na prevenção de conflitos e na construção da paz na região, sobretudo se houver articulação de interesses entre os Países partícipes em torno dos significados políticos das sugeridas "novas ameaças".

Uma interessante iniciativa seria, a exemplo da OTAN, a organização de uma universidade para pensar os temas pertinentes ao Atlântico Sul e à ZOPACAS. A OTAN possui a NATO Defense College criada em 1951, que é uma instituição voltada para a formação de militares. No caso da ZOPACAS, em contraponto à $\mathrm{OTAN}$, uma iniciativa nesse sentido não se limitaria apenas aos temas de defesa e à formação militar, incluindo, portanto, civis e outros 
temas relevantes à Zona de $\mathrm{Paz}$ e Cooperação visando sua integração e efetividade.

Nesse sentido, cabe lembrar que a União de Nações Sul-Americanas (UNASUL) possui o Centro de Estudos Estratégicos de Defesa do Conselho de Defesa Sul-Americano (CEED/CDS), além do Instituto Sul- Americano de Governo em Saúde (ISAGS).

Amorim (idem) chega a propor como uma "utopia, por exemplo, a criação de uma futura agência sul- americana de inteligência que pudesse integrar ações supra-nacionais no combate ao narcotráfico, tráfico de pessoas e outros ilícitos transnacionais", a mesma proposição caberia no contexto dos Países do Atlântico Sul via ZOPACAS, uma "agência integrada de inteligência do Atlântico Sul" que em si carregaria vetores de integração e, porventura, efetividade à Zona de Paz, sem sua necessária militarização, tal como se preconiza para a região.

Tal nível de cooperação é utópico, conforme Amorim (2012a), pois “as atividades de espionagem/contraespionagem se relacionam ao exercício do poder e ao uso ou ameaça de uso da violência, com uma particularidade que é de sempre ter por parâmetros os valores de um determinado grupo humano em relação a outros", o que evidentemente torna delicada a colaboração neste âmbito da vida social. Daí a necessidade de outros paradigmas e mentalidades em Inteligência, sobretudo visando à cooperação regional, evitando-se a violência e reduzindo-se as desconfianças, o que é almejado pela ZOPACAS.

$O$ contexto SISBIN/UNASUL é análogo ao SISBIN/ZOPACAS, de modo que se aplicam a ambos as conclusões apresentadas por Amorim (2012b), de que

"O caso brasileiro aponta tarefas a serem cumpridas pelos Países da região em matéria da regulação e inserção das AI em um Estado Democrático de Direito, e desde que se trata de um dos Países mais avançados nessa tratativa na América do Sul [e Atlântico Sul], tornam-se explícitas as assimetrias em termos das AI, entre os Países da UNASUL [e ZOPACAS], apontando para desafios futuros a uma consolidação da democracia na região."

Iniciativas de transparência e democracia no âmbito da ZOPACAS intensificariam as trocas entre os Países membros e, por conseguinte, sua 
efetividade. E, no caso brasileiro, trazer maior integração, efetividade e alinhamento de suas estruturas de segurança regional no Atlântico Sul, como preconizam os documentos públicos do País, justificando usos de recursos públicos em Inteligência e Defesa. Evidentemente, situação desejável aos demais Países da região.

Por fim, é importante destacar uma dimensão não menos importante à convergência de políticas entre o SISBIN e a ZOPACAS, de uma perspectiva brasileira. Trata-se das relações entre fluxo migratório internacional e os sistemas de segurança institucional do País.

Amorim (2012d) considera que

“o Brasil, no tocante às suas políticas migratórias, tem ainda se pautado pelo paradigma econômico e da segurança institucional, apesar da reforma do Estado brasileiro no tocante aos serviços de inteligência no País [...] No entanto, tal problemática não é exclusiva ao Brasil, mas perpassa todos os Países desenvolvidos, podendo-se afirmar que tal situação, no momento, é emblemática e estrutural."

A ZOPACAS e outros mecanismos multilaterais da política internacional pressupõem, além do movimento de mercadorias, o fluxo de pessoas. No caso do Brasil, há que se superar os preconceitos relativos aos povos de origem africana e aos pobres, sobretudo, caso se queira avançar na integração e na segurança regional. Esta não é uma tarefa simples, pois requer a transformação de mentalidades, que por vezes deita raiz profunda na História e na cultura brasileira.

\section{Conclusão}

A criação da ZOPACAS, em 1986, foi uma iniciativa brasileira no início de seu recente processo de democratização, ainda no contexto da Guerra Fria, a qual viria simbolicamente terminar três anos depois, o que desde logo exigiu a reformulação dos seus objetivos da Zona de Paz e Cooperação. Em seus 27 anos de existência, a ZOPACAS é marcada por uma baixa efetividade e pouco interesse dos Países membros.

Particularmente, o Brasil pouco priorizou a África em sua política externa, e apenas recentemente, nos governos Lula e Dilma, houve novas iniciativas em relação ao continente africano, denotando um crescente interesse 
estratégico dessa região para o Brasil, sobretudo após as descobertas de petróleo em águas profundas no Atlântico Sul.

Tal interesse estratégico brasileiro na ZOPACAS é declarado em seu LBDN, que também reconhece que o País carece de uma estrutura mais efetiva de Inteligência para a região, particularmente envolvendo o SINDE e o serviço de inteligência do MRE, com trocas de informações via SISBIN.

Por sua vez, o SISBIN ainda é uma obra incompleta do Estado brasileiro e carece de efetividade junto ao próprio Estado e à sociedade brasileira, sendo frágil a integração dos produtos de inteligência dos diversos serviços secretos que o compõem, tendo-se em vista a construção, consecução e acompanhamento de políticas públicas na área de Defesa e Segurança Internacional.

Por outro lado, no curto prazo, dado a diversidade de Países que compõem a ZOPACAS e a pluralidade de interesses envolvidos, torna-se pouco provável que cooperações regionais no âmbito da Inteligência se estabeleçam entre os Países participantes da Zona de Paz e Cooperação, reforçando as tradicionais desconfianças mútuas nesse setor da segurança internacional.

Mais que políticas internacionais para a efetividade de uma Paz que permita a coexistência pacífica entre os povos da Terra, tornam-se necessária a construção de novas mentalidades e, portanto, de uma Nova Política que não se paute pelo medo e as desconfianças. 


\section{Sérgio Gonçalves de Amorim}

\section{REFERÊNCIAS}

Amorim, Sérgio Gonçalves de. 2011. "Processo de institucionalização da Atividade de Inteligência no Brasil: alguns desafios à constituição de um Estado Democrático de Direito". Anais do VI Seminário do Programa de Pós-Graduação em Ciência Política da Universidade Federal Fluminense (UFF), Niterói (RJ), 09 a 11 de novembro. . 2012a. "Spy vs. Spy. Espionagem e contraespionagem - arte, ofício ou profissão?" Anais da 28 ${ }^{\mathrm{a}}$. Reunião Brasileira de Antropologia, São Paulo, 02 e 05 de julho.

- 2012b. "Perspectivas brasileiras de cooperação democrática em segurança regional - Integração do Sistema Brasileiro de Inteligência (SISBIN) à dinâmica da União de Nações Sul- Americanas (UNASUL)." Anais do $1^{\circ}$ Seminário Nacional de Pós-Graduação em Relações Internacionais, Brasília (DF), 12 e 13 de julho.

. 2012c. "Aperfeiçoamento institucional e organizacional das atividades de inteligência e consolidação de um estado democrático no Brasil." Anais do VI Encontro Nacional da Associação Brasileira de Estudos de Defesa (VI ENABED), São Paulo, 6 a 9 de agosto.

. 2012d. "Contextualização do debate brasileiro acerca das migrações internacionais - Uma análise a partir do caso haitiano." Anais do XVIII Encontro Nacional de Estudos Populacionais, ABEP, Águas de Lindóia/SP - Brasil, de 19 a 23 de novembro.

Brasil. 1999a. "Medida Provisória no 1.911-10", 24 de setembro.

. 1999b. “Lei Federal n. ${ }^{\circ} 9.883 ”$, de 07 de dezembro.

. 2002. "Portaria Normativa $\mathrm{n}^{\circ} 295 / \mathrm{MD}^{\prime}$, de 03 de junho.

. 2012. "Livro Branco da Defesa Nacional". Ministério da Defesa.

Costa, Wanderley Messias da. 2012. "Projeção do Brasil no Atlântico Sul: geopolítica e estratégia." Revista USP 95: 9-22.

Kornegay, Francis A. 2013. "South Africa, the South Atlantic and the IBSABRICS equation: the transatlantic space in transition." Austral: Brazilian Journal of Strategy \& International Relations, 2 (3): 75-100.

Lima, Marco Aurélio de Andrade. 2011. "A Iniciativa da Bacia do Atlântico: um risco para o Brasil?" Trabalho de Conclusão de Curso 
(Especialização - Curso de Altos Estudos de Política e Estratégia CAEPE) - Escola Superior de Guerra (ESG), Rio de Janeiro.

Migon, Eduardo Xavier Ferreira; e Carlos Alexandre Geovanini dos Santos. 2012. "África \& Brasil: parceria para o desenvolvimento." Anais do Seminário Brasileiro de Estudos Estratégicos Internacionais (SEBREEI), Porto Alegre, 20 a 22 de junho.

Miyamoto, Shiguenoli. 1987. “Atlântico Sul: zona de paz e de cooperação?” Lua $\begin{array}{lllll}\text { Nova } & 3 & (3): & 20-23 . & \text { Disponível em: }\end{array}$ $<$ http://www.scielo.br/scielo.php?script=sci_arttext\&pid=S0102$64451987000100005 \& \operatorname{lng}=\mathrm{en \& nrm}=\mathrm{iso}>$. Consultado em 24 de março de 2013.

Ribeiro, Cláudio Oliveira. 2010. “A política africana do Brasil no pós-guerra fria." Revista de Sociologia e Política 18 (35): 55-79. Disponível em: $<$ http://www.scielo.br/scielo.php?script=sci_arttext\&pid=S0104$44782010000100005 \& \operatorname{lng}=\mathrm{en \& nrm}=\mathrm{iso}>$. Consultado em 24 de março de 2013.

Saraiva, José Flávio Sombra. 2008. "A África na ordem internacional do século XXI: mudanças epidérmicas ou ensaios de autonomia decisória?" Revista Brasileira de Política Internacional 51 (1): 87-104. Disponível em: <http://www.scielo.br/scielo.php?script=sci_arttext\&pid=S0034$73292008000100005 \& \operatorname{lng}=\mathrm{en} \& n r m=\mathrm{iso}>$. Consultado em 30 de março de 2013.

. 2010. "The new Africa and Brazil in the Lula era: the rebirth of Brazilian Atlantic Policy." Revista Brasileira de Política Internacional 53 (especial): 169-182. Disponível em: $<$ http://www.scielo.br/scielo.php?script=sci_arttext\&pid=S0034$73292010000300010 \& \operatorname{lng}=\mathrm{en \& nrm}=\mathrm{iso}>$. Consultado em 30 de março 2013.

Souto Maior, Luiz A. P. 2003. "A ordem mundial e o Brasil". Revista Brasileira de Política Internacional 46 (2): 26-48. Disponível em: $<$ http://www.scielo.br/scielo.php?script=sci_arttext\&pid=S0034$73292003000200002 \& \operatorname{lng}=\mathrm{en \& nrm}=\mathrm{iso}>$. Consultado em 30 de março de 2013. 


\section{RESUMO}

O Brasil propôs com êxito, em 1986, a criação da Zona de Paz e Cooperação do Atlântico Sul (ZOPACAS), reunindo Países da América do Sul e África, visando evitar a propagação de armamento nuclear e de destruição em massa na região e sua consequente militarização. Em 1999, foi criado o Sistema Brasileiro de Inteligência (SISBIN) como parte de um processo de democratização da sociedade brasileira. Porém, considerando os respectivos contextos históricos e institucionais dessas duas iniciativas, não há, ainda, uma efetiva convergência entre ambas. De um lado, há uma diversidade de interesses por vezes conflitantes entre os Países que compõem a Zona de Paz, em suas demandas internas e externas de cada uma dessas sociedades; e de outro, da perspectiva brasileira, o SISBIN ainda não reflete uma ação integrada do Brasil na área da Inteligência Estratégica na área externa ao País, em particular no Atlântico Sul.

\section{PALAVRAS-CHAVE}

SISBIN; ZOPACAS; Inteligência; Atlântico Sul; Segurança Internacional. 